\title{
Depletion of Serotonin in the Nervous System of Aplysia Reduces the Behavioral Enhancement of Gill Withdrawal as Well as the Heterosynaptic Facilitation Produced by Tail Shock
}

\author{
David L. Glanzman, ${ }^{1}$ Steven L. Mackey, ${ }^{2}$ Robert D. Hawkins, ${ }^{2,3}$ Amy M. Dyke, ${ }^{1}$ Philip E. Lloyd, ${ }^{4}$ and Eric R. \\ Kandel1,2,3 \\ "Howard Hughes Medical Institute, ${ }^{2}$ Columbia University College of Physicians and Surgeons, ${ }^{3}$ New York State Psychiatric \\ Institute, New York, New York, 10032, and 4Department of Pharmacological and Physiological Sciences, University of \\ Chicago, Chicago, Illinois 60637
}

\begin{abstract}
Noxious stimuli, such as electrical shocks to the animal's tail, enhance Aplysia's gill- and siphon-withdrawal reflex. Previous experimental work has indicated that this behavioral enhancement, known as dishabituation (if the reflex has been habituated) or sensitization (if it has not been habituated), might be mediated, at least in part, by the endogenous monoaminergic transmitter serotonin (5-HT). To assess 5-HT's role in dishabituation and sensitization of Aplysia withdrawal reflex, we treated Aplysia with the serotonergic neurotoxin 5,7-dihydroxytryptamine (5,7-DHT). We found that 5,7-DHT treatment significantly reduced the dishabituation of the withdrawal reflex produced by tail shock. Treatment with the neurotoxin also blocked the heterosynaptic facilitation of monosynaptic connections between siphon sensory neurons and their follower cells, which contributes to the behavioral enhancement. Analysis by high-performance liquid chromatography indicated that 5,7-DHT treatment significantly reduced 5-HT levels in the Aplysia CNS. Moreover, the neurotoxic effects of 5,7-DHT appeared to be relatively specific for serotonergic pathways. Thus, 5,7-DHT treatment did not disrupt the ability of nonserotonergic facilitatory interneurons, the L29 cells, to facilitate the connections of siphon sensory neurons. Also, 5,7-DHT reduced 5-HT-dependent, but not dopamine-dependent, histofluorescence in Aplysia central ganglia. Finally, 5,7-DHT does not reduce the levels of the facilitatory peptides $\mathrm{SCP}_{\mathrm{A}}$ and $\mathrm{SCP}_{\mathrm{B}}$ within the Aplysia CNS. Our results, together with those of Mackey et al. (1989), indicate that 5-HT plays a major role in mediating dishabituation and sensitization of Aplysia's withdrawal reflex.
\end{abstract}

A variety of experimental evidence suggests that the monoamine serotonin (5-HT) mediates short-term behavioral dishabituation and sensitization of Aplysia's gill- and siphon-withdrawal response. Application of 5-HT mimics the known facilitatory effects of dishabituating or sensitizing stimuli (such as electrical

\footnotetext{
Received Feb. 27, 1989; revised June 6, 1989; accepted June 12, 1989.

This work was supported by the Howard Hughes Medical Institute and by NIH grants MH26212 (to R.D.H.) and NS23569 (to P.E.L.). We wish to thank Kathrin Hilten and Louise Katz for preparing the figures, and Harriet Ayers and Andrew Krawetz for typing the manuscript.

Correspondence should be addressed to Dr. David L. Glanzman, Howard Hughes Medical Institute, 722 West 168th St., New York, NY 10032.

Copyright (c) 1989 Society for Neuroscience $0270-6474 / 89 / 124200-14 \$ 02.00 / 0$
}

shocks to the animal's tail or head) on the neural circuitry underlying the withdrawal response. These facilitatory effects include broadening of the siphon sensory neuron's action potential (Klein and Kandel, 1978), increasing the sensory neuron's excitability (Klein et al., 1986), facilitation of transmitter release from the sensory neuron's terminals (Castellucci and Kandel, 1976), and reducing the feedback inhibition produced by firing of facilitatory interneurons (Frost et al., 1988). Moreover, 5-HT elevates levels of cAMP within siphon sensory neurons (Bernier et al., 1982). This elevation of intracellular cAMP is thought to mediate the molecular changes that underlie facilitation of transmission from sensory to motor neurons through cAMP-dependent protein phosphorylation (Klein and Kandel, 1978; Castellucci et al., 1982; Klein et al., 1982; Siegelbaum et al., 1982; Klein et al., 1986). Finally, immunohistochemical evidence indicates that 5-HT-containing varicosities lie close to the cell bodies and neuritic processes of the siphon sensory neurons, suggesting that these cells receive serotonergic innervation (Kistler et al., 1985; Longley and Longley, 1986).

Recent evidence, however, has made it clear that 5-HT is not the only facilitating transmitter for dishabituation and sensitization. Thus, the identified facilitatory interneurons in the Aplysia's abdominal ganglion (the L29 cells), which were once thought to be serotonergic on the basis of indirect evidence (Bailey et al., 1981, 1983), have now been shown not to contain 5-HT on the basis of both immunocytochemistry (Ono and McCaman, 1984; Kistler et al., 1985) and glyoxylic acid histofluorescence (Hawkins, 1989). Furthermore, in addition to the as-yet-unidentified transmitter of the L29 cells, the molluscan peptides $\mathrm{SCP}_{A}$ and $\mathrm{SCP}_{\mathrm{B}}$ have been shown to mimic the facilitatory actions of 5-HT (Abrams et al., 1984). Moreover, the SCP peptides also elevate cAMP levels in the siphon sensory neurons (Abrams et al., 1984).

To assess in more quantitative terms the role of 5-HT in dishabituation and sensitization of the gill- and siphon-withdrawal response, we have attempted to deplete serotonergic neurons in Aplysia of their transmitter using the serotonergic neurotoxin 5,7-dihydroxytryptamine (5,7-DHT). This substance, a cytotoxic analog of 5-HT, has been used successfully to deplete 5-HT in the nervous systems of both vertebrates (Baumgarten et al., 1982) and invertebrates (Livingstone et al., 1981; Glover and Kramer, 1982; Lent, 1984; Lent and Dickinson, 1984; Gadotti et al., 1986; Glanzman and Krasne, 1986). We have treated Aplysia with 5,7-DHT and found that this treatment reduces 
most of the behavioral enhancement of the gill-withdrawal response as well as the heterosynaptic facilitation of transmission at synapses between siphon sensory neurons and their follower cells produced by tail shock. Thus, our experiments provide evidence that 5-HT is a major transmitter for dishabituation and sensitization of the withdrawal reflex.

\section{Materials and Methods}

Animals. Adult Aplysia californica, weighing $50-85 \mathrm{gm}$, were obtained from either Marinus (Long Beach, CA) or Sea Life Supply (Sand City, CA). All animals had been caught in the wild. (We have found that 5,7DHT treatment produces significantly more nonspecific damage in laboratory-reared animals.) The animals were housed in tanks containing aerated artificial seawater (Instant Ocean) at a constant temperature of $15^{\circ} \mathrm{C}$, and were kept on a $12 \mathrm{hr}-12 \mathrm{hr}$ light-dark cycle.

5,7-DHT treatment. Experimental animals were given approximately $2 \mathrm{gm} / \mathrm{kg}$ of 5,7-DHT creatinine sulfate (Sigma) dissolved in a vehicle solution of artificial seawater (ASW) at a concentration of $10 \mathrm{mg} 5,7$ $\mathrm{DHT} / \mathrm{ml}$. The vehicle solution also contained $10 \mathrm{mg} / \mathrm{ml}$ sodium L-ascorbate (ICN) as an antioxidant. The drug was administered via intrahemocoel injections. Typically, experimental animals received 2 injections, spaced $48 \mathrm{hr}$ apart, a first injection of $75 \mathrm{mg} \mathrm{5,7-DHT}$, and a second of $50 \mathrm{mg}$. Control animals received 2 injections of the vehicle solution alone. (Occasionally, an experimental animal was judged, on the basis of criteria described below, to have received an insufficient dosage of the neurotoxin and was given a third injection of $25-50 \mathrm{mg} 5,7-\mathrm{DHT}$. In these instances, matched control animals, which had received the same number of injections and the same amount of the vehicle solution as these experimental animals, were included in the study.) Experimental manipulations were carried out $1-3 \mathrm{~d}$ after the final injection.

Behavioral tests. In our behavioral experiments we used a reduced preparation consisting of the dissected mantle organs, the tail, and the central nervous system, which was left connected to the tail and mantle organs via the tail nerves P9 and the siphon, branchial, and genitalpericardial nerves. Before being dissected the animals were anesthetized by injecting isotonic $\mathrm{MgCl}_{2}$ into the body cavity. The reduced preparation was pinned to the Sylgard base of a small chamber filled with circulating ASW and the siphon was pinned to prevent it from moving. A mechanical tapper driven by a solenoid was positioned above the siphon, and the gill was attached to an isotonic movement transducer (Harvard Biosciences) with a silk suture tied to the base of the posterior pinnule. The $\mathrm{MgCl}_{2}$ was then flushed out of the tissue by perfusing the gill with seawater through a cannula inserted into the afferent vein and by injecting the body wall of the tail with several volumes of ASW. The preparation was continuously perfused with ASW for at least $60 \mathrm{~min}$ before an experiment was begun. Test stimulation to the siphon consisted of a 10-hz train of 5 taps, each $60 \mathrm{msec}$ in duration. The tip of the tapper was soft plastic, $1 \mathrm{~mm}$ in diameter. The force of the taps (approximately 5-10 gm) was adjusted to produce a modest gill contraction before an experiment was begun. Sensitizing/dishabituating tail stimulation consisted of a train of $460-\mathrm{Hz}$ AC electrical shocks $(1.5$ sec on, 1.5 sec off, $25 \mathrm{~mA}$ ) delivered via hand-held capillary electrodes. It was not possible for the tail shock to be delivered "blind," since the 5,7-DHT-treated preparations could sometimes be distinguished from controls by skin lesions or discoloration of the hemolymph. However, both control and toxin-treated preparations exhibited maximal gill contractions in response to the shock (see Fig. 3), suggesting that delivery of the shock was approximately equal for the 2 groups.

Electrophysiological tests. We examined the effects of 5,7-DHT treatment on the neural circuitry mediating the gill- and siphon-withdrawal. Animals were anesthetized by an injection of isotonic $\mathrm{MgCl}_{2}$ (approximately $50 \%$ of an animal's body weight). The animal was completely bisected by cutting through the body wall approximately one-third of the animal's length up from the tip of the tail, and the anterior twothirds of the animal was discarded. The dissection left the posterior portion of the animal, including all of the general tail region (see Walters et al., 1983, figure 2), intact and connected to the CNS via both of the posterior pedal nerves. After the dissection was completed, the central ganglia were briefly $(1 \mathrm{~min})$ dipped into a solution of $0.5 \%$ glutaraldehyde in normal ASW to facilitate desheathing. Then the entire preparation was transferred to a 2-chambered, Sylgard-lined dish. The central ganglia were placed in one chamber, which contained $50 \%$ isotonic
$\mathrm{MgCl}_{2} / 50 \% \mathrm{ASW}$; the tail region was placed in the second chamber, which contained normal ASW. The posterior pedal nerves connecting the central ganglia to the tail were led through a small slot in a plastic barrier between the 2 chambers; this slot was sealed with Vaseline. The tail was loosely restrained by pinning it to the bottom of the chamber. The $\mathrm{MgCl}_{2}$ anesthetic was then flushed out of the tail by injecting approximately $10 \mathrm{ml}$ of normal ASW into the body wall of the tail. Typically, the tail recovered its motility and reflex responsiveness a few minutes afterward. The abdominal ganglion was partially desheathed. Then the chamber containing the central ganglia was perfused at a constant rate with aerated normal ASW. After perfusing the nervous system for approximately $30 \mathrm{~min}$, we began electrophysiological recording. Intracellular recordings were made at room temperature (20$24^{\circ} \mathrm{C}$ ) with glass capillary microelectrodes containing $3 \mathrm{M} \mathrm{KCl}$. Electrode resistances were $12-15 \mathrm{M}$. Intracellular electrophysiological potentials were amplified and recorded using standard equipment and techniques. Tail stimulation for the electrophysiological experiments consisted of a train of four $60-\mathrm{Hz}$ AC shocks ( $1.5 \mathrm{sec}$ on, $1.5 \mathrm{sec}$ off, $25 \mathrm{~mA}$ ) delivered via capillary electrodes and was identical to that used in the behavioral experiments.

HPLC analysis. We quantified the loss of 5-HT and dopamine (DA) produced by the 5,7-DHT treatment in central ganglia of Aplysia through high-performance liquid chromatography (HPLC) together with electrochemical detection. The left pleural-pedal and abdominal ganglia from 10 Aplysia-5 that had received injections of 5,7-DHT (as described above) and 5 that had received control injections-were dissected free from their connecting tissue in $50 \%$ isotonic $\mathrm{MgCl}_{2} / 50 \%$ ASW. All nerves were trimmed short and the bag cell clusters were trimmed from the abdominal ganglia. The 3 ganglia from each animal were transferred together to a 2 -ml glass tissue grinder tube containing $200 \mu \mathrm{l}$ of $0.1 \mathrm{M}$ acetic acid. This tube was heated for $5 \mathrm{~min}$ at $100^{\circ} \mathrm{C}$, after which the ganglia were homogenized. The homogenate was transferred to a 1.5-ml Eppendorf tube. Another $300 \mu \mathrm{l}$ of $0.1 \mathrm{M}$ acetic acid was then added to the grinding tube and the tube vortexed to rinse any remaining homogenate from its walls. This acetic acid rinse was also transferred to the Eppendorf tube. The homogenized ganglia were stored in the Eppendorf tubes at $-70^{\circ} \mathrm{C}$ until analyzed. For analysis, the homogenized ganglia were thawed and centrifuged for $20 \mathrm{~min}(55,000 \mathrm{rpm}$ at $2^{\circ} \mathrm{C}$. The supernatant was then transferred to $1.5 \mathrm{ml}$ Eppendorf tubes with Pasteur pipettes and lyophilized. Each sample (containing the extract of 3 ganglia from a single animal) was redissolved in $0.1 \mathrm{M}$ acetic acid; for each HPLC run 1/500 of the total sample was used. The HPLC analysis was performed with an Isco $\mu \mathrm{LC}$ system together with a Bioanalytical Systems (BAS) LC-48 amperometric detector. The monoamines were eluted isocratically with a C18 $1 \mathrm{~mm} \times 150 \mathrm{~mm}$ microbore column. The mobile phase consisted of $50 \%$ acetonitrile with $25 \mathrm{~mm}$ formic

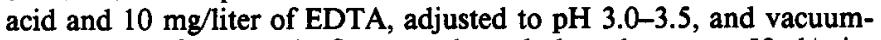
degassed and filtered. The flow rate through the column was $50 \mu \mathrm{l} / \mathrm{min}$, the column pressure 3000 PSI. The potential across the electrode of the amperometric detector was $0.7 \mathrm{~V}$. We recorded the current output of the amperometric detector on chart paper with a chart recorder. The amount of a monoamine in the chromatographic peak was quantified by xeroxing the chart records, cutting out the peaks, and weighing them. The 5-HT and DA content of the sample peaks was calculated by comparing them to HPLC peaks from external standards of 5-HT and DA run at the same time as the samples.

$S C P$ bioassay. In addition to quantifying the amount of 5-HT and DA in ganglia from 5,7-DHT-treated and control Aplysia, we also quantified the amount of the peptides SCP in ganglia from toxin-treated and control animals. Abdominal and left pleural-pedal ganglia from 5 control and 5 toxin-treated animals were dissected out, heated to $100^{\circ} \mathrm{C}$, and homogenized as described above. The homogenate was then centrifuged at $10,000 \mathrm{~g}$ for $10 \mathrm{~min}$, filtered through a $0.45-\mu \mathrm{m}$ filter, lyophilized, and run on reverse-phase HPLC. This reverse-phase HPLC was carried out on a Brownlee C-8 RP 300 column with a gradient developed from $15 \% \mathrm{CH}_{3} \mathrm{CN}, 85 \% \mathrm{H}_{2} \mathrm{O}$ to $23 \% \mathrm{CH}_{3} \mathrm{CN}, 77 \% \mathrm{H}_{2} \mathrm{O}$ in $11 \mathrm{~min}$. Trifluoroacetic acid $(0.01 \mathrm{M}$, Pierce) was included in both the $\mathrm{CH}_{3} \mathrm{CN}$ and $\mathrm{H}_{2} \mathrm{O}$. Column fractions were divided into 2 duplicates, lyophilized, and the amount of SCP-like bioactivity determined in each duplicate using an isolated Helix heart bioassay (Lloyd, 1978) with synthetic $\mathrm{SCP}_{\mathrm{B}}$ (Peninsula) as a standard.

Morphological analysis. We examined the histofluorescence of central ganglia from 2 toxin-treated and 2 control animals which were processed simultaneously with glyoxylic acid (see Hawkins, 1989, for methodological details). 


\section{Results}

\section{Effects of the 5,7-DHT injections: General observations}

Jahan-Parwar et al. (1987) have previously described the shortterm behavioral effects of 5,7-DHT injections in Aplysia, and our observations are consistent with theirs. Specifically, upon being injected with the neurotoxin, all experimental animals contracted into a ball and inked copiously. Several minutes after these responses the toxin-injected animals began to display continual pedal and parapodial waves characteristic of locomotion in this animal. However, as described by Jahan-Parwar et al. (1987), the animals did not actually locomote because they were unable to attach their feet to a substrate. Also, frequently their righting reflex was impaired, so that they simply contracted in ineffectual pedal waves while lying on their sides. Typically, the control animals did not ball or ink after injections of the vehicle solution; within minutes they were always found resting quietly in their holding pans, apparently unperturbed, and indistinguishable from noninjected animals. Behavioral differences between experimental and control animals persisted for at least $24 \mathrm{hr}$ after the initial injection. By $24 \mathrm{hr}$ after the second injection, experimental animals showed few spontaneous movements; they lay on their sides, unattached to the substrate, with their parapodia open, their mantle organs distended. Nonetheless, most continued to show withdrawal responses to such stimuli as pinches to their rhinophores or taps to their siphons or gills. Approximately $25 \%$ of toxin-treated animals did not exhibit such withdrawal responses and were excluded from the study.

One difference between our observations and those of JahanParwar et al. (1987) is that they report that the behavioral differences between 5,7-DHT-treated and control animals in their study disappeared by $2-3 \mathrm{hr}$ after the injections. The persistence of abnormal behaviors in our experimental animals was undoubtedly due to the higher dosages of 5,7-DHT that the animals in our study received (on the order of $2 \mathrm{gm} / \mathrm{kg} \mathrm{vs} 10 \mathrm{mg} / \mathrm{kg}$ in the Jahan-Parwar et al. study).

\section{5,7-DHT treatment reduces dishabituation of the withdrawal reflex produced by tail shock}

We first asked what effect the 5,7-DHT injections have on the ability of tail shocks to enhance the gill-withdrawal response. To answer this question, we carried out behavioral experiments using semiintact preparations in 10 control and 10 5,7-DHTtreated Aplysia (Fig. $1 A$ and Materials and Methods). The experimental protocol is outlined in Figure $1 B$. On each trial, a $10-\mathrm{Hz}$ train of 5 brief taps was delivered to the siphon and the maximum amplitude of gill withdrawal in the next $7 \mathrm{sec}$ was recorded. Stimulation and recording were both controlled automatically by an IBM PC with a Modular Instruments, Inc. (Southeastern, PA) interface. There were a total of 9 trials of siphon stimulation with a 2-min intertrial interval. Approximately $15 \mathrm{sec}$ after Trial 4, a train of 4 electric shocks was delivered to the tail via capillary electrodes.

Representative results from the behavioral experiments are shown in Figure 2A. Both the control and 5,7-DHT-treated preparations gave a robust gill withdrawal to the first siphon stimulus. By the fourth preshock trial, the amplitude of gill withdrawal had declined for both preparations; this decline reflects the previously described behavioral habituation of this response (Pinsker et al., 1970). Following the tail shocks, the gill withdrawal was dishabituated in the control preparation but
A
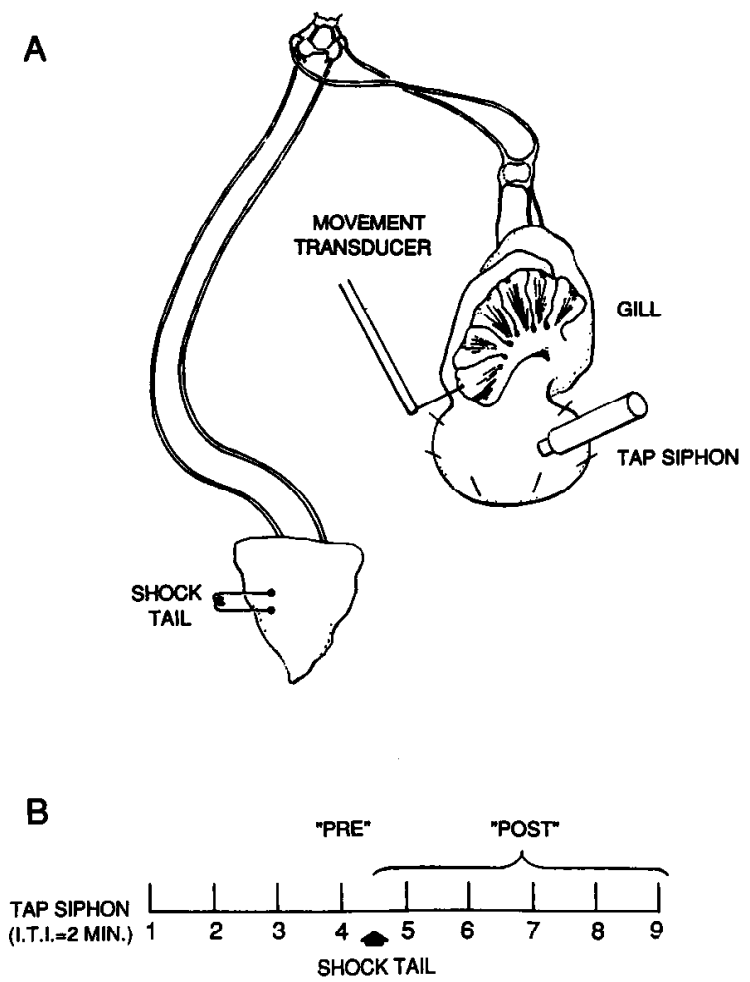

Figure 1. Preparation and protocol for behavioral tests of 5,7-DHTs effects. $A$, Schematic diagram of the reduced preparation used in the behavioral experiments which consisted of the entire CNS, except for the buccal ganglia, together with the excised mantle organs and the tail. Both P9 nerves, which connect the tail to the pedal ganglia, were left intact, as were the branchial, siphon, and genital-pericardial nerves connecting the abdominal ganglion to the mantle and other organs. $B$, Experimental protocol. Taps of a constant force were delivered to the siphon with a mechanical tapper once every $2 \mathrm{~min}$, and the amplitude of the gill's contraction was measured with a movement transducer. Four preshock trials were carried out, and then approximately $15 \mathrm{sec}$ after the fourth trial four $60-\mathrm{Hz}$ AC shocks (1.5 sec on, $1.5 \mathrm{sec}$ off, 25 $\mathrm{mA}$ ) were delivered to the preparation's tail with a pair of capillary electrodes. Following the tail shock, 5 postshock trials were performed.

not in the experimental preparation. The average behavioral data are summarized in Figure $2 B$. Because the data were not normally distributed, nonparametric statistics were used. The median amplitude of gill withdrawal on the first trial was not significantly different between the control and experimental preparations (1.16 vs $1.62 \mathrm{~mm}$ ), although there was a tendency for the experimental group to have larger responses. Both groups showed significant habituation from Trial 1 to Trial 4 (Wilcoxon $T=6.5, p<0.05$ one-tail for the control group and $T=0, p$ $<0.05$ two-tail for the experimental group). The relative decline in the amplitude for the response from Trial 1 to Trial 4 was the same for both groups (Trial $4=28 \%$ of Trial 1 ). Thus, the 5,7-DHT treatment did not interfere with behavioral habituation. By contrast, the toxin treatment did interfere with dishabituation of the gill withdrawal in response to tail shock: only in the control group was the response significantly enhanced (Wilcoxon $T=10, p<0.05$, one-tail, comparing the average of Trials 5-9 to Trial 4). Moreover, the amount of enhancement produced by the shocks was significantly greater for the control group than for the experimental group (Post $=928 \%$ of Pre for the control group and $119 \%$ for the 5,7-DHT group, MannWhitney $U=19, p<0.05$, two-tail). This difference in disha- 
A

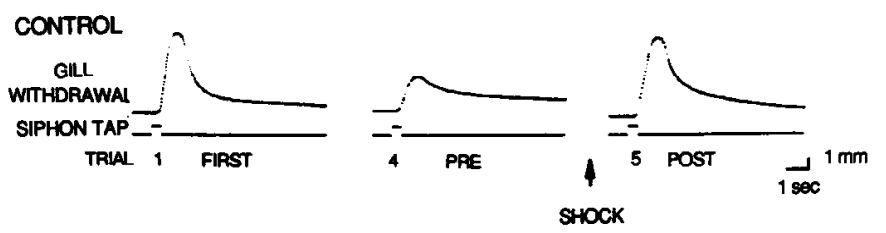

5, 7- DHT
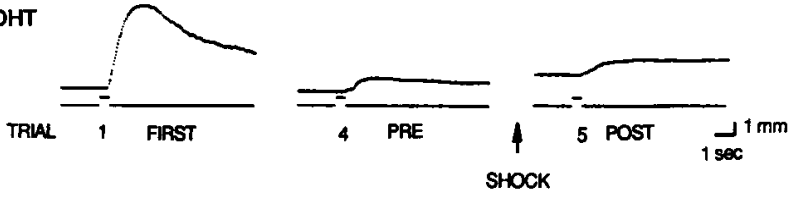

B

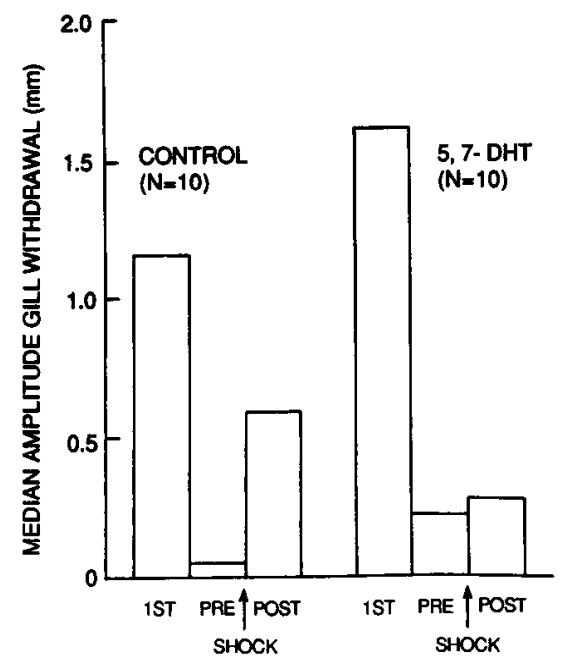

Figure 2. Results from the behavioral experiments. $A$, Sample records from experiments on a control and a 5,7-DHT-treated preparation. For each experiment the individual records from Trials 1,4 , and 5 are shown. Each record represents the response of the gill, as measured with a movement transducer, to a siphon tap. $B$, Graph presenting the group data from the behavioral experiments. The data are expressed as medians since they were non-normally distributed. For both groups the median results for the first and fourth (Pre) trials are shown; the Post bars represent the average of the responses on Trials 5-9. The interquartile ranges for the control animals were $0.13-4.38(1 s t), 0.03-0.10$ (Pre), and 0.41-1.01 (Post); for the 5,7-DHT animals they were 0.51 5.58 (1st), 0.07-0.68 (Pre), and 0.13-0.80 (Post). The dishabituation produced by the tail shock was significantly greater for the control group than for the experimental group (Mann-Whitney $U=19, p<0.05$, twotail).

bituation is unlikely to be due to the experimental animals having been in poor condition or generally unresponsive to stimuli due to nonspecific effects of the toxin injections. First, the responses to siphon tap on Trial 1 indicated that preparations from 5,7-DHT-treated animals were, if anything, more responsive than control preparations. Second, both groups showed maximal gill contractions to the tail shocks, although there was a tendency for the gills of control preparations to remain contracted somewhat longer (Fig. 3A).

\section{A parallel component of behavioral dishabituation and sensitization is also affected by 5,7-DHT treatment}

Pinsker and his colleagues (Kanz et al., 1979) have shown that, in addition to enhancing evoked gill contractions, noxious stimuli also increase the frequency of spontaneous gill contractions
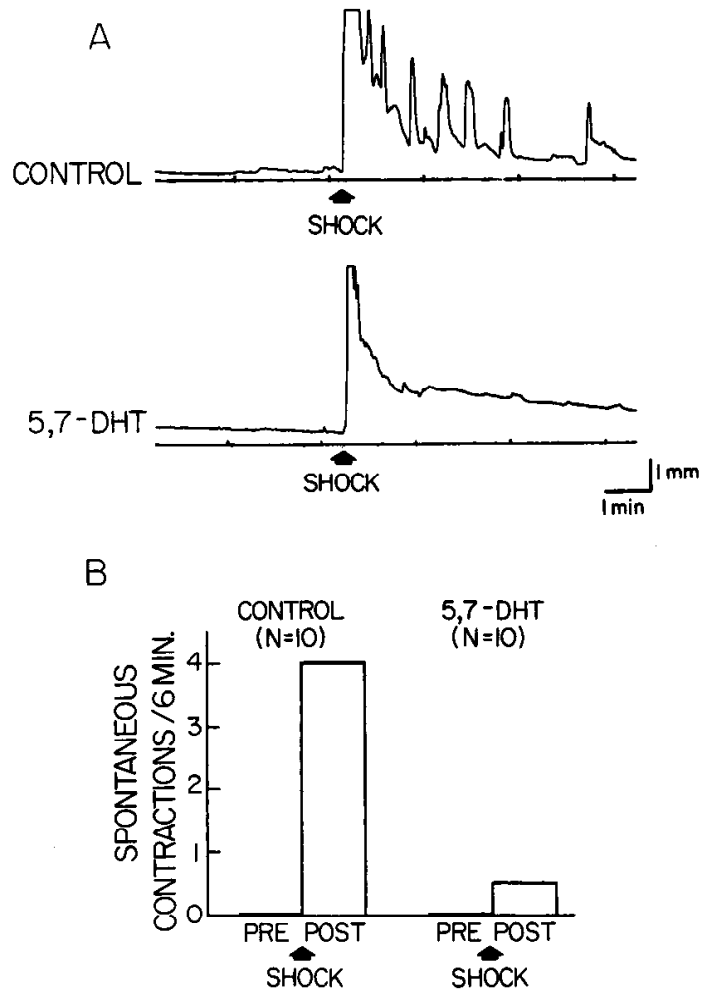

Figure 3. Tail shock produces significantly more spontaneous gill contractions in control than in 5,7-DHT preparations. $A$, Sample records from behavioral experiments on a control preparation and a 5,7-DHTtreated preparation. Note that the tail shocks directly elicited maximum gill contraction from both preparations. Following the shock, the control preparation exhibited several spontaneous (nonevoked) gill contractions whereas the toxin-treated preparation did not. $B$, Group data expressed as the median number of spontaneous gill contractions exhibited by control and toxin-treated preparations during the $6 \mathrm{~min}$ before tail shock (Pre) and the $6 \mathrm{~min}$ after tail shock (Post). The interquartile ranges for the control animals were 0-1 (Pre) and 0-7 (Post); for the 5,7-DHT animals they were $0-0$ (Pre) and $0-1$ (Post). Tail shock produced a significantly greater increase in spontaneous contractions in the control than in the experimental group (Mann-Whitney $U=27, p<0.05$, onetail).

associated with respiratory pumping in Aplysia. These respiratory-related contractions can also be evoked by siphon stimulation, and they contribute to dishabituation and sensitization. In the course of our behavioral experiments, we found that 5,7DHT treatment disrupts this parallel component of behavioral dishabituation and sensitization. Representative results are shown in Figure $3 A$. Following tail shock, the control preparation exhibited a series of spontaneous gill contractions (defined as any nonevoked contraction $>1.5 \mathrm{~mm}$ ), whereas the toxintreated preparation did not. Figure $3 B$ summarizes the data for the 2 groups. Spontaneous contractions were infrequent for both the control and the experimental preparations prior to tail shock. However, the rate of spontaneous contractions significantly increased after tail shock in the control group (Wilcoxon $T=1$, $p<0.05$, comparing the number of spontaneous contractions during the $6 \mathrm{~min}$ immediately before and immediately after tail shock) but not in the experimental group. Moreover, the increase in spontaneous contractions produced by tail shock was significantly greater in the control preparations than in the toxintreated preparations (median Post-Pre $=2.5$ for the control group and 0 for the experimental group, Mann-Whitney $U=$ $27, p<0.05$, one-tail). 
A

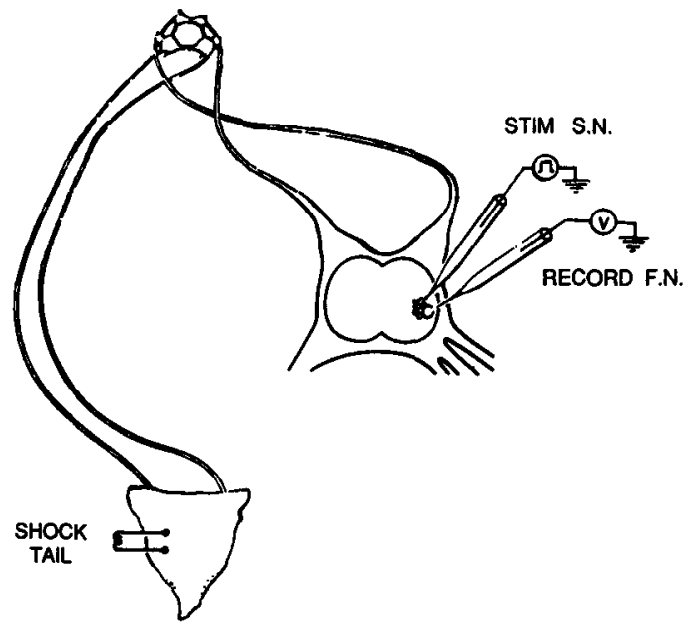

B

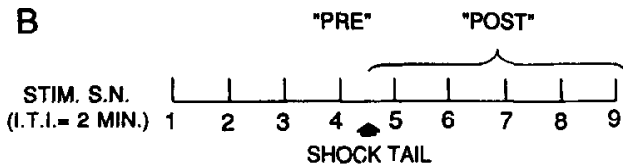

Figure 4. Preparation and protocol for the electrophysiological tests of 5,7-DHT's effects. $A$, Schematic drawing of the reduced preparation used in electrophysiological experiments which consisted of the CNS, except for the buccal ganglia, together with the tail. As in the behavioral experiments, the tail was left connected to the central ganglia via the P9 nerves. The abdominal ganglion was desheathed and then a siphon sensory neuron (S.N.) and one of its follower neurons (F.N.) (i.e., a neuron with which the sensory neuron had a monosynaptic excitatory connection) were impaled with intracellular electrodes. $B$, Experimental protocol for the electrophysiological tests. As in the behavioral experiments, 4 preshock trials were performed followed by 5 postshock trials. Each trial consisted of causing the sensory neuron to fire once by intracellular stimulation and then recording the resulting monosynaptic EPSP in the follower neuron. Tail shocks were the same as those used for the behavoral tests.

We have obtained similar results for both evoked and spontaneous contractions using mantle shock instead of tail shock (for the evoked contractions, Post $=1138 \%$ of Pre for the control group and $240 \%$ for the 5,7-DHT group, Mann-Whitney $U=$ $66, p<0.05$ one-tail; for the spontaneous contractions, median Post-Pre $=5$ for the control group and 1 for the 5,7-DHT group, $U=46, p<0.01$ two-tail; $N=15$ per group). This suggests that the serotonergic system mediates the behaviorally enhancing effects of noxious stimuli to at least 2 different sites on the animal.

\section{5,7-DHT treatment blocks the facilitation of the connections between siphon sensory neurons and their follower cells produced by tail shock}

Our behavioral experiments suggested that 5-HT mediates behavioral dishabituation, in part, by activating a serotonergic pathway. To determine whether 5-HT also mediates facilitation of the monosynaptic component of the reflex produced by tail shock, we carried out electrophysiological experiments using the reduced preparation shown in Figure $4 A$. We impaled individual siphon sensory (or LE) cells with intracellular microelectrodes and stimulated them while simultaneously recording intracellularly from follower cells within the abdominal ganglion. Most, if not all, of the follower cells in these experiments, as indicated
A
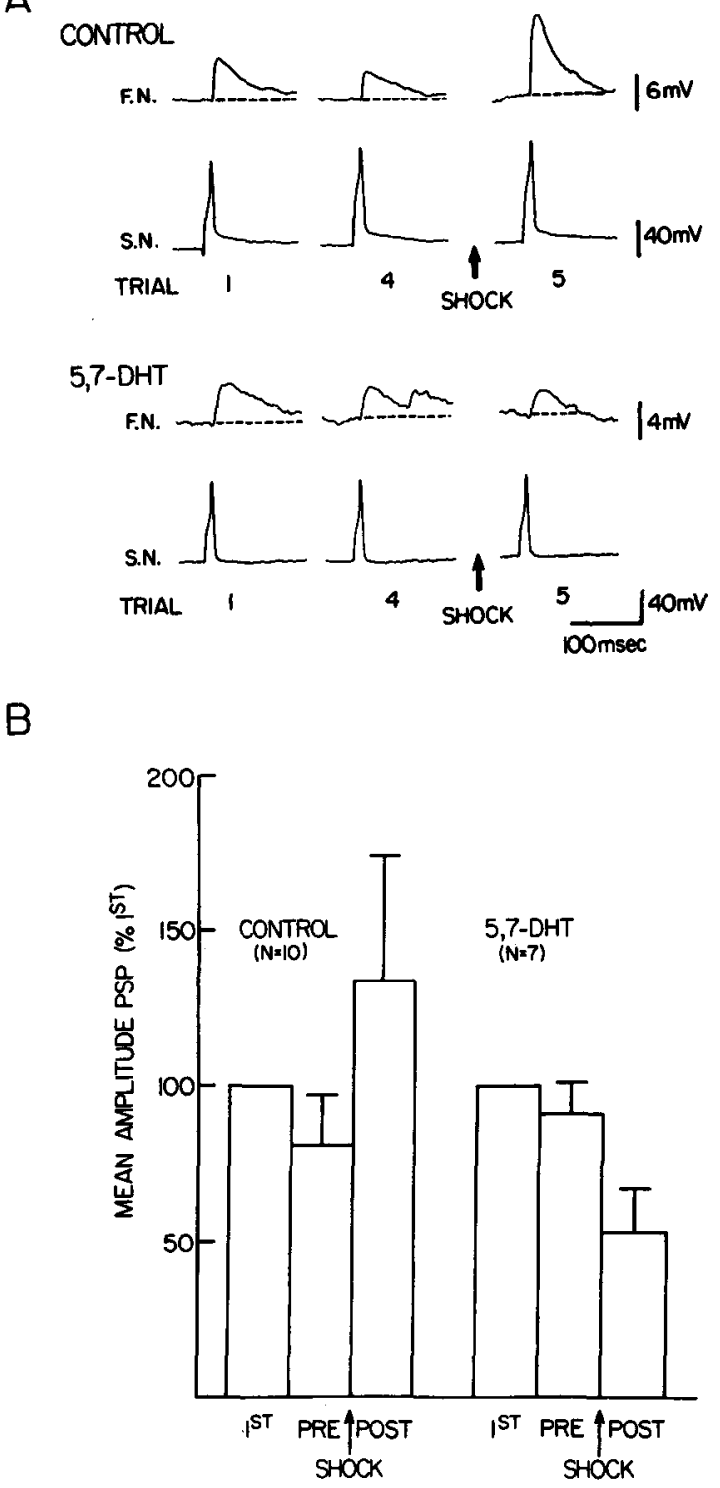

Figure 5. Results from the electrophysiological tests. $A$, Sample intracellular records from electrophysiological experiments on a control and a 5,7-DHT-treated preparation. The records show the intracellularlyrecorded sensory neuron (S.N.) action potential and the resulting EPSP in the follower neuron $(F . N$.) for Trials 1,4 , and 5. B, Graph presenting the group results. The amplitudes of the PSPs are normalized as the percent of the EPSP on the first trial. Error bars represent SEM. The histograms present the mean PSP amplitudes from the first and fourth (Pre) trials of each experiment as well as the mean of the average EPSP from Trials 5-9 (Post). Tail shock produced significantly more facilitation of the PSP in the control preparations than in the toxin-treated preparations $(t=2.79, p<0.05$, two-tail).

by their position within the ganglion and by their morphological appearance, were probably members of the class of siphon motor neurons known as the small siphon motor (or LFS) cells (Frost, 1987). The protocol in these experiments was analogous to that used for the behavioral experiments (Fig. $4 B$ ). Sensory cells were stimulated intracellularly in order to produce single spikes at 2 $\min$ ITI. The motor neuron was hyperpolarized $30 \mathrm{mV}$. The amplitude of the monosynaptic EPSP was measured in the follower motor neuron (either the peak height or the height of the first inflection point if the EPSP was complex). Four preshock 
A

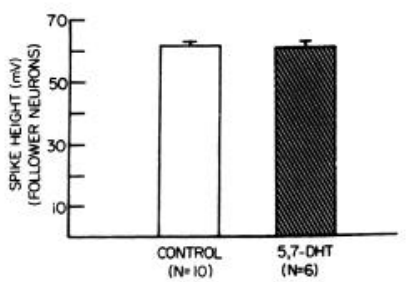

B

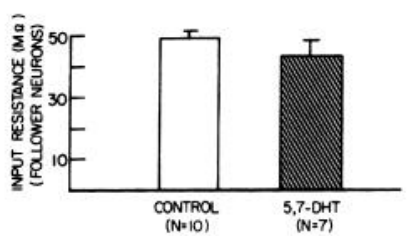

Figure 6. Comparisons of electrical properties of follower neurons from control and 5,7-DHT-treated preparations (the same preparations as were used for the electrophysiological tests summarized in Fig. 5). $A$, Mean height of spikes elicited from follower neurons. $B$, Mean input resistance (as determined by intracellular injections of hyperpolarizing current pulses) of follower neurons. There were no significant differences between follower neurons from the control and toxin-treated preparations ( $p>0.5$ for both measures).

trials were given; $1 \mathrm{~min}$ after the fourth Pre trial the tail of the preparation was shocked, and then 5 more postshock trials were given. Experiments were performed on 10 control and 7 5,7DHT-treated preparations.

Representative results from these electrophysiological experiments are shown in Figure 5A. From Trial 1 to Trial 4 the EPSP in both the control and the 5,7-DHT preparations declined; this decline represents the monosynaptic depression previously described at the synapse between siphon sensory neurons and their follower neurons and contributes to short-term behavioral habituation of the withdrawal reflex (Castellucci et al., 1970; Kupfermann et al., 1970). Tail shock produced facilitation of the EPSP in the control preparation, but not in the experimental preparation (Trial 5). The group data are summarized in Figure $5 B$. Parametric statistics were used because the data were approximately normally distributed. The ampli-

tudes of the EPSPs for each experiment were normalized to the amplitude of the EPSPs on Trial 1. There was no significant difference between the mean amplitudes of the EPSPs on Trial 1 for the control or experimental groups, although there was a tendency for experimental preparations to have larger initial EPSPs (control mean $=4.39 \pm 1.02$ vs experimental mean $=$ $5.23 \pm 1.23 \mathrm{mV}$ ). Both groups showed modest synaptic depression from Trial 1 to Trial 4 (Trial $4=81 \pm 16 \%$ of Trial 1 for controls and $91 \pm 10 \%$ for experimentals). This depression was not significant for either group, nor were the 2 groups significantly different from each other. Control preparations, however, exhibited significant heterosynaptic facilitation following tail shock (Student's $t=1.86, p<0.05$, one-tail, comparing the mean amplitude of the EPSPs on Trials 5-9 to the amplitude of the EPSP on Trial 4), while 5,7-DHT-treated preparations did not. Moreover, the amount of facilitation in control preparations was significantly greater than that in 5,7-DHT-treated preparations (Post $=164 \%$ of Pre for the control group and $58 \%$ for the experimental group, $t=2.79, p<0.05$, two-tail).

The inability of tail shocks to facilitate the LE-to-followercell synapses in 5,7-DHT-treated preparations might have been due to nonspecific actions of the toxin. However, the toxintreated preparations appeared otherwise normal by a variety of physiological criteria. First, there were no significant differences between control and experimental preparations in either the height of the action potentials or the input resistance of the follower neurons (Fig. 6). Second, application of both 5-HT ( $N$ $=2)$ and $\operatorname{SCP}_{\mathrm{B}}(N=1)$ to 5,7-DHT-treated preparations produced facilitation of the monosynaptic LE-to-follower-cell EPSP (Fig. 7). Finally, we observed no consistent differences between control and 5,7-DHT-treated preparations in the response of follower cells to the tail shocks. In both groups the follower cells were typically strongly depolarized and caused to fire by the

A
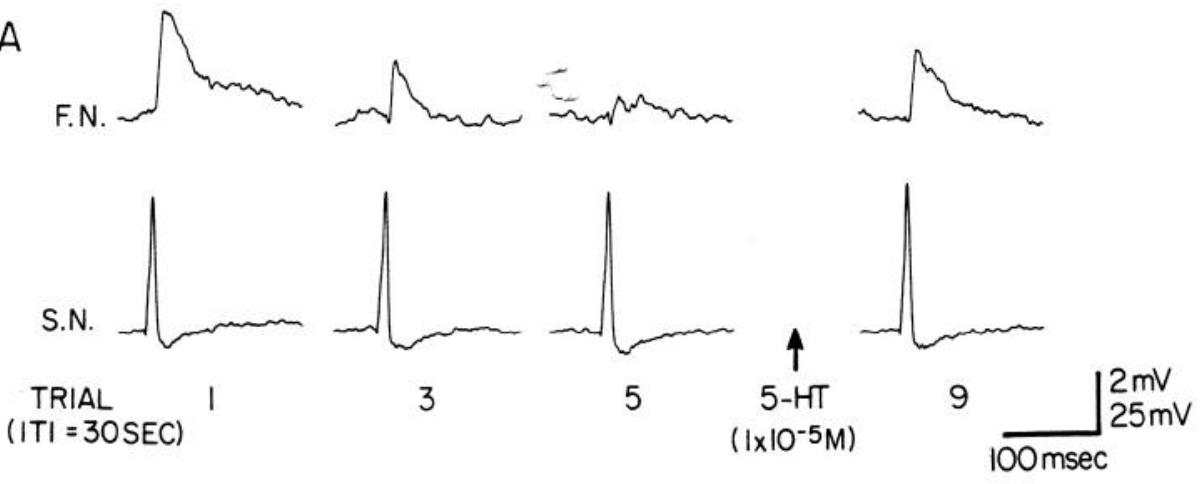

B
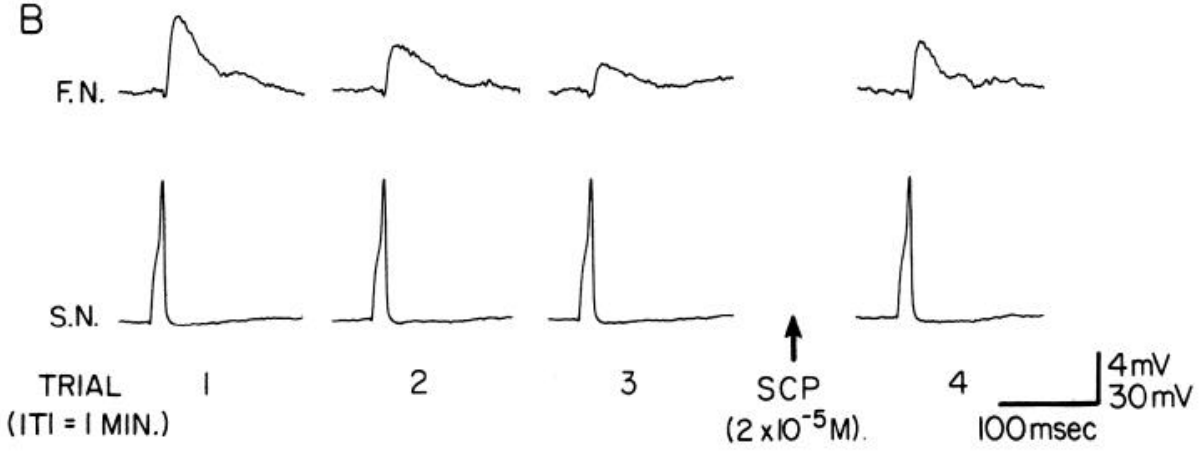

Figure 7. Both 5-HT and $\mathrm{SCP}_{\mathrm{B}}$ can facilitate the monosynaptic siphon sensory neuron-follower neuron EPSP following 5,7-DHT treatment. $A$, Effect of 5-HT application on the sensory-follower synapse in an abdominal ganglion from an animal treated with 5,7DHT. The sensory neuron was fired once per $30 \mathrm{sec}$. After the fifth trial, 5-HT was added directly to the bath to a final concentration of $1 \times 10^{-5} \mathrm{M}$. $B$, Effect of $\mathrm{SCP}_{\mathrm{B}}$ application on the sensory-follower synapse after 5,7-DHT. The sensory neuron was fired once per $1 \mathrm{~min}$. After the third trial, $\mathrm{SCP}_{\mathrm{B}}$ (concentration $2 \times 10^{-5} \mathrm{M}$ ) was spritzed onto the ganglion with a microsyringe. 


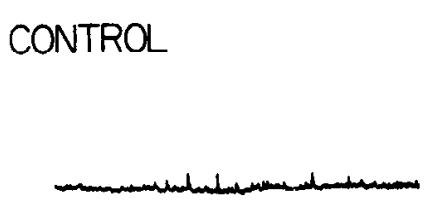

PRE SHOCK

Figure 8. Examples of the effects of tail shock on follower neurons in control and 5,7-DHT-treated preparations. The figure shows representative intracellular recordings from the follower cells both before and after tail shock. Notice that the shocks strongly depolarized the cells in both preparations and also increased the frequency of spontaneous PSPs. Spikes in the records were clipped by the pen recorder.

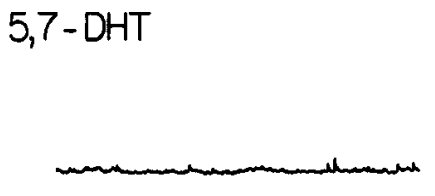

PRE SHOCK

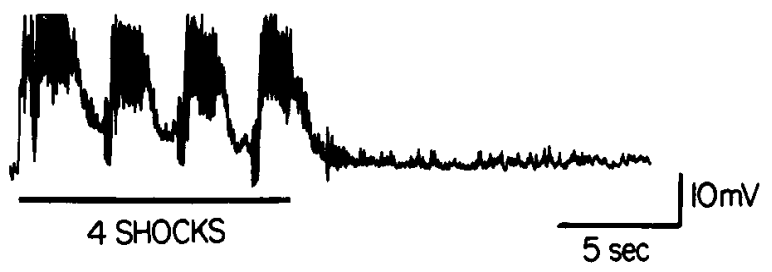

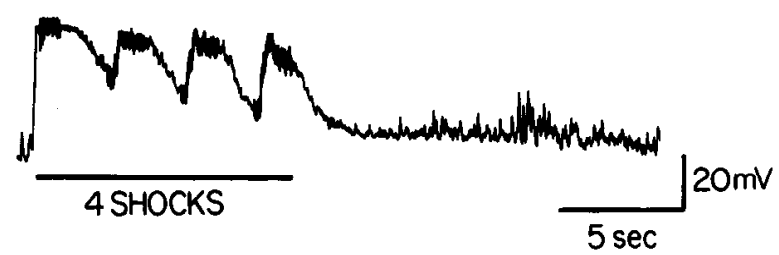

shocks. Also, following the shocks there was a prolonged enhancement of spontaneous EPSPs in the follower cells (Fig. 8). Finally, as we show below, other nonserotonergic facilitating systems do not appear to be disrupted by 5,7-DHT treatment.

\section{L29 interneurons can facilitate the connections of siphon sensory neurons in 5,7-DHT-treated abdominal ganglia}

The L29 cells are a group of excitatory interneurons within the Aplysia's abdominal ganglion. There are approximately 5 per ganglion. They receive monosynaptic excitatory input from the LE sensory neurons, and they directly excite some siphon motor neurons, particularly the LFS cells (Hawkins et al., 1981a; Frost, 1987). Moreover, L29 cells are activated by tail shock and can presynaptically facilitate the connections made by LE sensory neurons when stimulated (Hawkins et al., 1981b; Hawkins and Schacher, 1989). It seems likely, therefore, that the capability of the L29 cells to facilitate the connections of the sensory neurons plays a role in behavioral dishabituation and sensitization of Aplysia's withdrawal response. (See Frost et al., 1988, for additional ways that $\mathrm{L} 29$ cells participate in dishabituation and sensitization.) As mentioned earlier, the L29 cells are not serotonergic (Ono and McCaman, 1984; Kistler et al., 1985; Hawkins, 1989; Hawkins and Schacher, 1989). Consequently, we wished to know whether the L29 cells were adversely affected by the 5,7-DHT treatment. This was a particularly crucial test of the specificity of the neurotoxin's action. Indeed, a priori, it seemed possible, if not likely, that the toxin might affect L29 cells since these interneurons have an uptake system for 5-HT (Bailey et al., 1983) and might therefore also take up 5,7-DHT. We therefore tested whether intracellular stimulation of an L29 cell could facilitate the LE-to-follower-cell synapse in 5,7-DHTtreated preparations. For these tests we used 3 preparations from the electrophysiological experiments described above. The L29 tests were carried out approximately $30 \mathrm{~min}$ after testing for tail-shock-induced facilitation. In 2 of the 3 preparations highfrequency intracellular stimulation of an L29 cell facilitated LE-to-follower-cell connections (including, in one case, the connection between the LE cell and the L29 itself (Fig. 9A). Since, even in normal abdominal ganglia, not every L29 appears to facilitate sensory-to-motor connections (only $27 \%$ produced significant facilitation in the Hawkins et al., 1981b, study), we conclude that the 5,7-DHT injections do not deplete L29 cells of their facilitatory transmitter. Moreover, other synaptic outputs of $\mathrm{L} 29$ cells, as well as their synaptic inputs, appear normal in 5,7-DHT-treated preparations. Thus, our ability to identify L29 cells in toxin-treated preparations indicates that the reciprocal connections between $\mathrm{L} 29 \mathrm{~s}$ and $\mathrm{L} 30$ cells were intact since these connections are used to identify L29 cells (see Hawkins et al., 1981a). Also, Frost (1987) has reported that firing of L29 cells produces both a fast and a slow EPSP onto LFS siphon motor neurons. We tested this connection between L29 and LFS cells in one toxin-treated preparation and found it unimpaired (Fig. 9B). Finally, we found that tail shock is able to recruit L29 cells in 5,7-DHT-treated preparations (Fig. 9C). We did not, however, quantitatively compare the recruitment of L29 by tail shock in control and toxin-treated preparations.

\section{5,7-DHT treatment depletes 5-HT in central ganglia of Aplysia}

Having determined that 5,7-DHT treatment significantly reduces the behavioral and physiological effects of tail shock, we next quantified the effect of the toxin treatment on 5-HT levels in Aplysia central ganglia by means of HPLC. Representative chromatograms from the HPLC analysis are shown in Figure 10. As the chromatograms indicate, the chromatographic peak for 5-HT was smaller in extracts of ganglia from 5,7-DHTtreated animals than in extracts of ganglia from controls. The HPLC data are summarized in Figure 11. The mean 5-HT content of combined pleural, pedal, and abdominal ganglia from controls $(N=5)$ as indicated by the HPLC analysis was $362 \pm$ $19 \mathrm{pM}$, while that for the combined ganglia from experimentals $(N=5)$ was $150 \pm 19 \mathrm{pM}$. This reduction in 5-HT content produced by the 5,7-DHT injections was statistically significant $(t=4.08, p<0.01$, two-tail).

To examine the specificity of 5,7-DHT's neurotoxic action, we also attempted to measure the amount of another endogenous monoamine, DA, in the control and experimental ganglia. However, it was difficult to quantify the DA chromatographic peaks in our HPLC analysis in the case of ganglia from toxintreated animals. This was because the DA peaks eluted on the falling phase of a large breakthrough peak or series of peaks (which may represent, in part, 5-HT metabolites resulting from the 5,7-DHT treatment); consequently, the baseline of the DA 


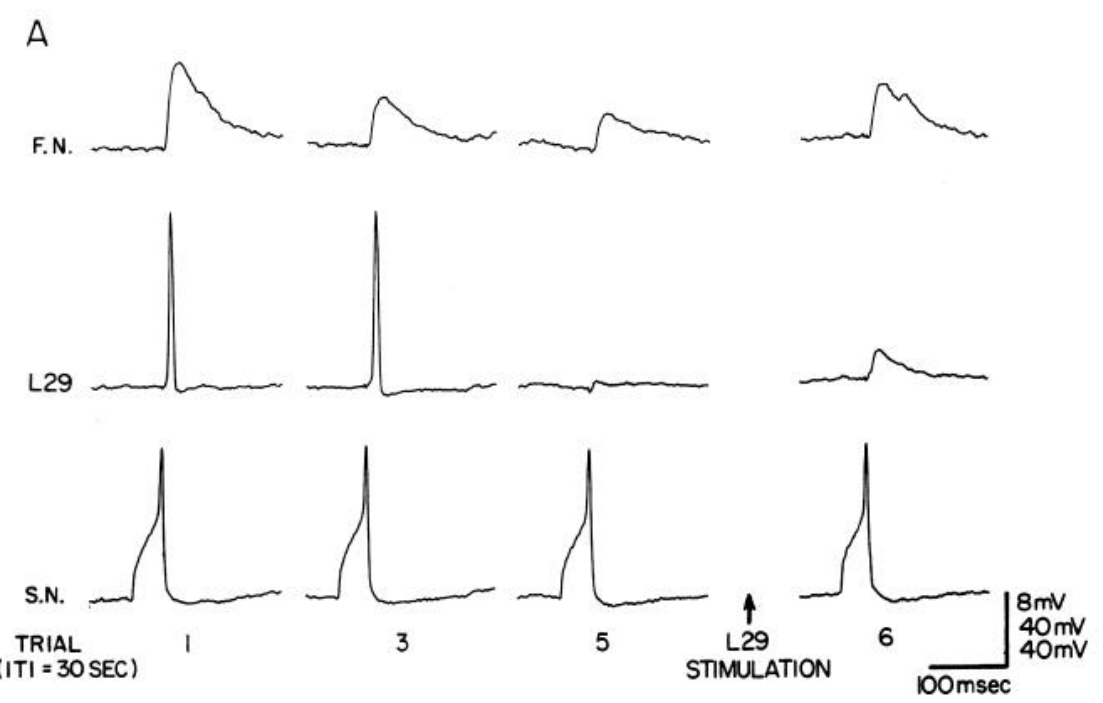

B
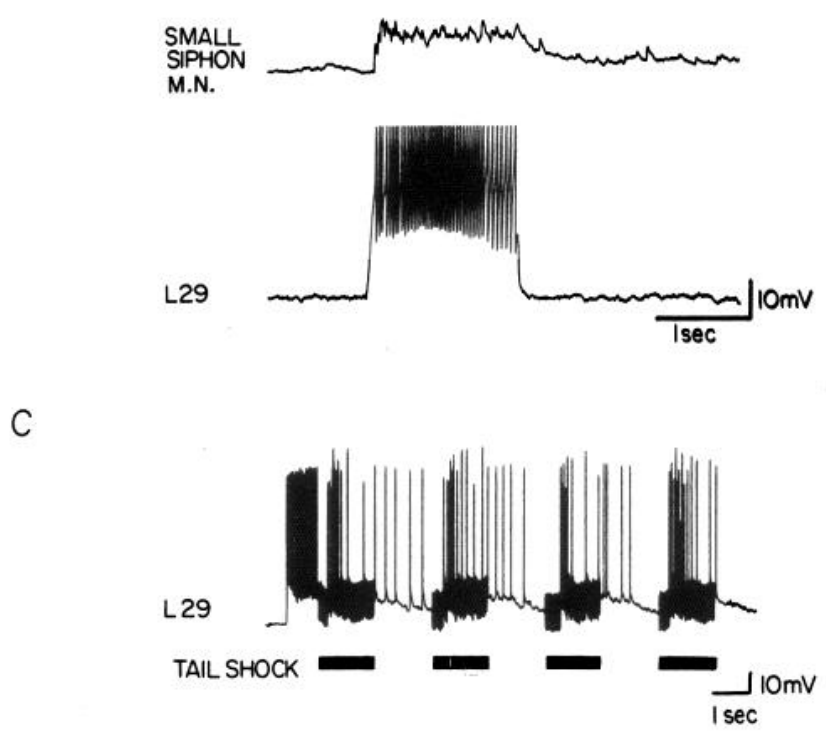

Figure 9. Connections of L29 are intact following 5,7-DHT treatment. $A$, Facilitation of the connections of a siphon sensory neuron by stimulation of L29 in a preparation which has received 5,7-DHT treatment. In this experiment a sensory neuron (S.N.), one of its follower neurons (F.N.), and an L29 neuron were impaled with intracellular electrodes. The $S . N$. was fired by intracellular stimulation at a rate of once per $30 \mathrm{sec}$ and the resulting responses recorded in the L29 and F.N. Notice that during the first 5 trials the connections of the S.N. exhibited homosynaptic depression. Immediately following the fifth trial the L29 cell was made to fire at a high frequency for 5.5 sec (approximately 150 spikes) through intracellular stimulation. The L29 stimulation facilitated not only the synapse between the $S . N$. and $F . N$. but also that between the $S . N$. and the L29 itself. $B$, Responses produced in a small siphon motor neuron (M.N.) by L29 stimulation in a 5,7-DHT-treated preparation. As shown previously (Frost, 1987), intracellular stimulation of L29 produces both fast EPSPs and a slow EPSP in M.N.s of this class. Both types of excitatory responses are apparent following toxin treatments, as these records indicate. Notice, too, the gaps in L29's firing. The gaps are due to IPSPs from L30 interneurons, which are recruited by firing of L29s (Hawkins et al., 1981a). Thus, 5,7-DHT treatment also does not interfere with the reciprocal connections between $\mathrm{L} 29$ and $\mathrm{L} 30$ cells. $C$, Tail stimulation can elicit firing from L29 cells following 5,7-DHT treatment. Intracellular recording of an L29 cell's response to tail stimulation in a toxin-treated preparation. The burst of L29 spikes before the onset of the shocks is in response to the capillary electrodes simply being placed against the skin of the tail. peaks could not be determined unequivocally (Fig. 10). However, under the assumption that the shoulder of the breakthrough peak represented the baseline, we cut out and weighed the DA peaks from the chromatographs for ganglia from the 5 control and 5 toxin-treated animals as we had done for the 5-HT peaks (see Materials and Methods). Our measurements indicated that the mean DA content from the control ganglia was $259 \pm 8 \mathrm{pM}$, while that from the 5,7-DHT ganglia was $216 \pm$ $21 \mathrm{pM}$. This difference was not statistically significant $(p>0.1)$. We therefore tentatively conclude that the 5,7-DHT injections do not significantly affect levels of DA, at least in the combined pleural, pedal, and abdominal ganglia of Aplysia (see, however, the Discussion).

\section{5,7-DHT treatment reduces 5-HT histofluorescence in Aplysia central ganglia}

Previous studies employing 5,7-DHT, or its isomer, 5,6-DHT, to deplete 5-HT in the central nervous system of vertebrates (e.g., Nobin et al., 1973; Frankfurt and Azmitia, 1984) and invertebrates (Glover and Kramer, 1982; Lent and Dickinson,
1984; Glanzman and Krasne, 1986) have reported that these neurotoxins reduce 5-HT histo- or immunofluorescence. To determine whether 5,7-DHT also reduces the 5-HT-dependent histofluorescence of serotonergic neurons in the Aplysia nervous system, we used the technique of glyoxylic acid staining (de La Torre and Surgeon, 1976; Hawkins, 1989). This fluorescence microscopy technique has the advantageous feature that it stains DA-containing as well as 5-HT-containing neurons. The 2 different monoamines fluoresce at different wavelengths when the appropriate filter combination is used. The glyoxylic acid results therefore provided us with another test of the relative specificity of 5,7-DHT's effect.

We compared glyoxylic-treated central ganglia from 3 animals that had received control injections and 3 that had received injections of 5,7-DHT. As expected from previous 5-HT immunohistochemical work (Ono and McCaman, 1984; Kistler et al., 1985; Longley and Longley, 1986), abdominal ganglia from control animals contained many cell bodies of various sizes, which showed bright 5-HT (yellow) histofluorescence, as well as dense regions of serotonergic fibers in the central neuropil 
CONTROL

(1/500 PL-PED-ABD)

Figure 10. Sample records from the HPLC analysis. One pleural, pedal, and abdominal ganglion from both a control and a 5,7-DHT-treated animal were processed (see Materials and Methods) and then fractions from control and toxin-treated ganglia were injected within minutes of each other onto the HPLC column. In addition, known amounts of 5-HT and DA were injected onto the column for use as standards. The records represent the current output of the amperometric detector. Arrows point to the chromatographic peaks corresponding to 5-HT and DA. Note that the DA peak was difficult to quantify in the samples from 5,7-DHTtreated animals because it rode on the shoulder of a large breakthrough peak evident in the record shown here.

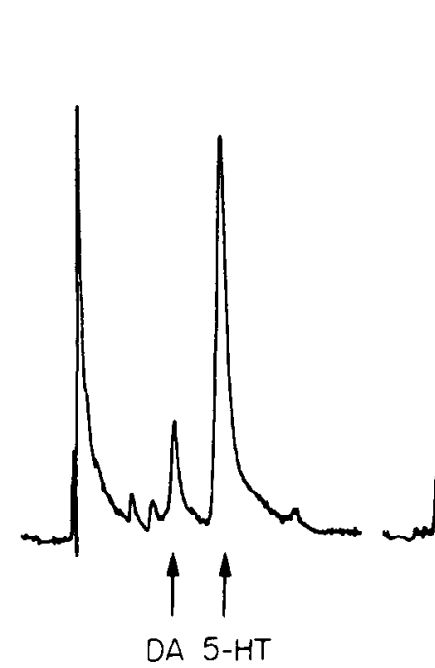

5,7-DHT

STANDARDS

(0.5 pmol) and a network of serotonergic varicosities surrounding many of the nonserotonergic cell bodies in the ganglion (Fig. 12All ). In abdominal ganglia from toxin-treated animals (Fig. 12 $A_{2}$ ), the histofluorescence of sertonergic cell bodies was weaker, although still visible. Also, experimental ganglia had smaller regions of 5-HT histofluorescent neuropil than did control ganglia. The most striking difference between control and experimental abdominal ganglia, however, was that the experimental ganglia lacked the network of serotonergic fibers and varicosities surrounding nonserotonergic cell bodies. Both experimental and control abdominal ganglia had comparable regions of bright DA (blue) histofluorescent fibers in the central neuropil. Thus, DA histofluorescence in the abdominal ganglion appeared unaffected by the 5,7-DHT treatments. The differences between the glyoxylic acid results for control and toxin-treated ganglia were most apparent in the buccal ganglia. These bilaterally symmetrical ganglia contain no serotonergic cell bodies, but possess a rich network of serotonergic fibers and varicosities, which appear to surround all of the cell bodies in the ganglia (Fig. 12 $B_{I}$ ). Treatment with 5,7-DHT had no apparent effect on the histofluorescence of DA-containing structures in the buccal ganglia, but entirely eliminated the 5-HT histofluorescence (Fig. 12B $\mathrm{B}_{2}$ ). The glyoxylic acid results support the conclusion from the HPLC analysis that 5,7-DHT's effects within Aplysia's CNS were relatively specific for serotonergic pathways, although our histofluorescence technique would not be adequate to detect small quantitative differences in DA staining between control and experimental ganglia.

\section{5,7-DHT does not reduce the SCP content of Aplysia central ganglia}

In the HPLC and glyoxylic acid experiments we examined the neurotoxin's effect on only one other endogenous transmitterDA. Moreover, DA has a presynaptic inhibitory effect on the siphon sensory neurons (Abrams et al., 1984). Thus, these experiments do not address the issue of whether 5,7-DHT might deplete other endogenous transmitters besides DA, and, in particular, whether it might deplete other transmitters that have facilitatory actions on the sensory neurons for the gill- and siphon-withdrawal response. We found, through electrophysio- logical experiments, that 5,7-DHT does not disrupt one known facilitatory pathway - the one which comprises the L29 neurons. We also wished to know 5,7-DHT's effect on neurons containing the other known facilitatory transmitters, $\mathrm{SCP}_{\mathrm{B}}$ and $\mathrm{SCP}_{\mathrm{A}}$. Since SCP-containing facilitatory interneurons have not yet been identified, we compared the levels of the SCPs in central ganglia from control and 5,7-DHT-treated Aplysia using a bioassay (Lloyd, 1978). As in the HPLC analysis, we combined individual pleural, pedal, and abdominal ganglia from 5 control and 5 experimental animals. The bioassay results showed no difference in SCP content between control and toxin-treated ganglia $(p>$ 0.5 ; Fig. 13).

\section{Discussion}

The effect of 5,7-DHT in the nervous system of Aplysia The present study demonstrates that injections of the toxic 5-HT analog 5,7-DHT produce a significant depletion of 5-HT within the Aplysia CNS, as determined by HPLC analysis. Our study therefore adds to the growing body of work in which this neurotoxin has been shown to deplete 5-HT within the CNS of a variety of invertebrates (Glover and Kramer, 1982; Lent, 1984; Goldberg and Kater, 1985; Gadotti et al., 1986; Glanzman and Krasne, 1986). Moreover, our glyoxylic acid results indicate that 5,7-DHT had a more disruptive effect on serotonergic neurotransmission within the Aplysia CNS than might be predicted from the HPLC results. Thus, 5,7-DHT treatment almost entirely eliminated histofluorescent staining of serotonergic varicosities and small fibers, the presumptive release sites for 5-HT. We did not test the efficacy of transmission at specific serotonergic synapses in Aplysia after 5,7-DHT treatment. However, in a study of 5,7-DHT's effect within the CNS of the gastropod mollusc Helisoma, Gadotti et al. found that 5,7-DHT significantly disrupted synaptic transmission from an identified serotonergic neuron $(\mathrm{C} 1)$ to a follower motor neuron.

\section{5,7-DHT is relatively specific for serotonergic pathways in Aplysia}

The neurotoxic effect of 5,7-DHT appeared relatively specific for serotonergic pathways within the Aplysia CNS. The neu- 
rotoxin did not significantly reduce the content of another endogenous Aplysia monoamine, DA, in combined pleural, pedal, and abdominal ganglia (see also Gadotti et al., 1986). Gadotti et al. did, however, find a small (18\%) but statistically significant reduction in the DA content of 5,7-DHT-treated buccal ganglia of Helisoma. We saw no apparent differences between the DAdependent staining in control and buccal ganglia with glyoxylic acid treatment. But since we did not measure 5-HT and DA levels in the buccal ganglia of Aplysia with HPLC, and since the glyoxylic acid technique is admittedly not quantitative, we cannot rule out a modest effect of 5,7-DHT on dopaminergic pathways in Aplysia. However, DA presynaptically inhibits transmitter release from the siphon sensory neurons. Therefore, depletion of DA within the abdominal ganglion would be expected to counteract the antifacilitatory effect of 5-HT's depletion; that is, depletion of DA by 5,7-DHT should work against the major findings of the present study. Also, 5,7-DHT had no apparent effect on pathways containing other endogenous neurotransmitters which, like 5-HT, presynaptically facilitate transmitter release from siphon sensory neurons $-\mathrm{SCP}_{\mathrm{A}}, \mathrm{SCP}_{\mathrm{B}}$, and the as-yet-unidentified L29 transmitter.

Further evidence of 5,7-DHT's selectivity for serotonergic pathways in Aplysia comes from the observation by Jahan-Parwar et al. (1987) and by us that, initially, injections of 5,7-DHT have behavioral effects, such as inducing locomotion, that mimic those produced by injecting 5-HT itself into Aplysia (see Mackey and Carew, 1983). This suggests that 5,7-DHT may bind to serotonin receptors within the Aplysia CNS, or that it may cause release of the transmitter from the terminals of serotonergic neurons, or perhaps both. Jahan-Parwar et al. found that 5,7-DHT has an agonist effect on the membrane currents of some Aplysia neurons like that of 5-HT, although it was 510 times less potent than 5-HT. Moreover, we have found that 5,7-DHT, like 5-HT, broadens the action potentials of siphon sensory neurons although it was approximately an order of magnitude less potent (D. L. Glanzman and S. L. Mackey, unpublished observations). Despite these observations, it seems unlikely that an agonist effect can fully account for 5,7-DHT's dramatic behavioral effects. Oxidation of 5,7-DHT in physiological saline is extremely rapid (on the order of minutes), even in the presence of an antioxidant (sodium L-ascorbate). Yet many animals in our study displayed abnormal locomotor activity a day after an injection of the neurotoxin. The peristence of abnormal behaviors such as abnormal locomoting following 5,7-DHT treatment may therefore be due, in part, to the depleting action of the neurotoxin, i.e., to the prolonged release of 5-HT from serotonergic neurons. The fact that 5,7-DHTtreated preparations tended to have larger initial gill-withdrawal responses to siphon taps than did controls is suggestive, particularly in light of the recent demonstration that chronic application of 5-HT can produce long-term facilitation of the synapse between LE cells and gill motor neurons (Montarolo et al., 1986). It may be that synapses between the sensory neurons and their follower cells were already somewhat facilitated by a toxininduced release of 5-HT from the terminals of facilitatory interneurons before we began our tests.

\section{The role of 5-HT in the dishabituation and sensitization of} Aplysia's withdrawal responses

Our results, together with those of Mackey et al. (1989), indicate that 5-HT has an important role in mediating the dishabituation of Aplysia's gill- and siphon-withdrawal response produced by
PL-PED.-ABD.

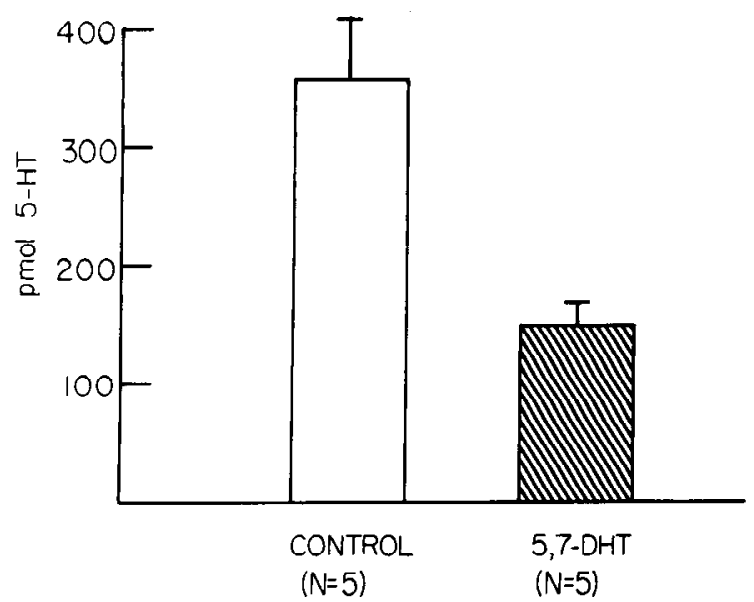

Figure 11. Quantification of the results from the HPLC analysis of the 5-HT content of central ganglia from control and 5,7-DHT-treated animals. The histogram shows the mean 5-HT content for the 2 groups; the error bars represent SEM. The difference in 5-HT content between ganglia from control and 5,7-DHT-treated animals was statistically significant ( $t=4.08, p<0.01$, two-tail).

noxious stimuli such as tail shock. However, our results also raise several questions. Perhaps the most prominent of these is why following 5,7-DHT treatment we saw so little evidence of the other facilitatory pathways - the L29 and SCP pathwaysthought to be operative during sensitization and dishabituation. Tail shocks can activate L29 interneurons after 5,7-DHT treatment (see Fig. 9) and might also activate SCP-containing facilitatory interneurons. Why, then, was there no apparent contribution of these nonserotonergic interneurons in our experiments on 5,7-DHT-treated animals? One possible answer is that the effects of the different facilitatory transmitters are not additive, but synergistic. If so, then the experimental deletion of any one transmitter might be expected to drastically reduce the net facilitatory effect of the others. Another possibility is that 5,7DHT treatment reduces the extent to which the tail shocks actually recruit nonserotonergic facilitatory interneurons. If so, this would imply that 5-HT not only directly facilitates synaptic connections made by the sensory neurons within the abdominal ganglion, but also that it either recruits, or facilitates recruitment of, L29, SCP, and, possibly, other facilitatory pathways. Yet a third possible explanation for the apparent absence of residual facilitation following 5,7-DHT treatment derives from the recent finding (Mackey et al., 1987; Marcus et al., 1988) that tail shocks inhibit, as well as enhance, Aplysia's gill- and siphonwithdrawal response. This inhibition is thought to be mediated by neurons containing the peptide FMRFamide as well as, perhaps, by DA-containing neurons (Abrams et al., 1984; Mackey et al., 1987; Hawkins and Small, 1988). Thus, the presence of nonserotonergic facilitatory pathways after 5 -HT depletion might have been masked by the countervailing inhibition elicited by tail shock.

Recent behavioral experiments on juvenile Aplysia (Rankin and Carew, 1988) and adults (Marcus et al., 1988) indicate that dishabituation (i.e., an increase in the response above a habituated value) and sensitization (i.e., an increase in the response above an initial, unhabituated value) of gill- and siphon-withdrawal can be experimentally dissociated. This raises the pos- 

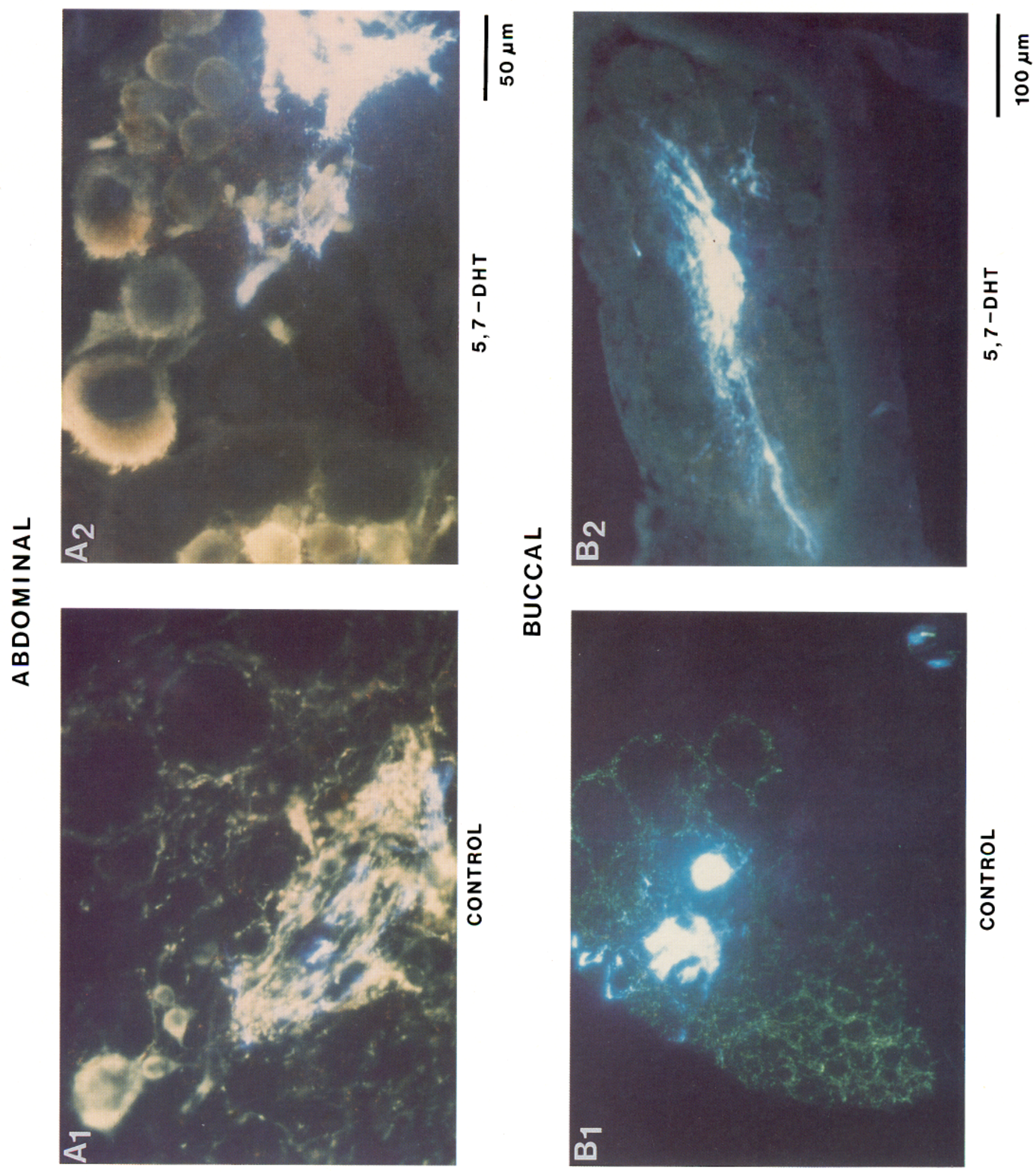

过

5
$\mathbf{1}$
1
1
ம

త্

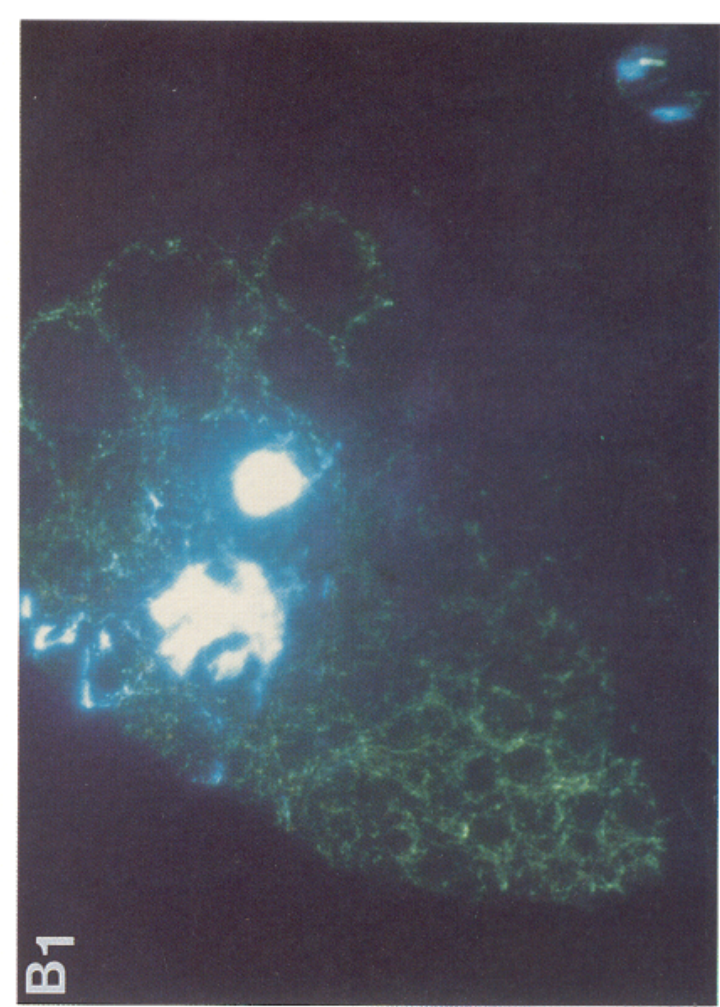

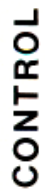


sibility that these 2 behavioral phenomena might be mediated by qualitatively different underlying facilitatory processes. The experiments of Hochner et al. (1986)-who found that 5-HT can presynaptically facilitate transmitter release from the siphon sensory neurons through 2 independent cellular processes, one of which (spike broadening) is ineffective when transmitter release is severely depressed in the sensory neurons-have been taken as support for this possibility. However, it is probable that in most behavioral situations synaptic depression is in the intermediate range, so that both of the cellular processes described by Hochner et al. contribute. Moreover, one can explain the behavioral data of Carew and his colleagues without invoking 2 separate underlying facilitatory processes. The differences between dishabituation and sensitization might be due, on a cellular level, purely to parametric factors, among which is the degree to which the dishabituating/sensitizing stimuli recruit the competing inhibitory process. For these reasons we believe 5-HT is critical not only to dishabituation of the withdrawal reflex, as our behavioral data demonstrate, but also to sensitization.

Recent work of Zakharov and Balaban (1987), who studied the withdrawal reflexes of the terrestrial snail Helix lucorum, supports the notion that 5 -HT plays a critical role in molluscan behavioral sensitization. In experiments like those of Rankin and Carew, Zakharov and Balaban found that behavioral sensitization of withdrawal due to tactile stimulation of the snail's head is exhibited by adult Helix but not by juvenile snails less than 1 month old. Zakharov and Balaban also found, in experiments analogous to the present ones, that such sensitization is absent in adult Helix treated with 5,7-DHT. Finally, their histochemical investigations showed that there was a gradual increase of serotonergic neurons in the CNS of Helix during development. Newborn snails have no 5-HT-containing neurons, while adults have 5-HT-containing neurons in all central ganglia; 4-month-old snails have an intermediate number, with 5-HT-containing neurons in some, but not all ganglia. (See Nolen et al., 1986, for data regarding the development of 5-HTcontaining cells in the Aplysia CNS.) Zakharov and Balaban conclude that the reason for the absence of sensitization in snails under 1 month old and in adult snails treated with 5,7-DHT is the same: the lack of a serotonergic facilitatory system.

An interesting question is whether 5-HT is critical only to the enhancement of gill- and siphon-withdrawal or, instead, to the enhancement of all the various responses of Aplysia seen following tail shock (e.g., tail withdrawal, escape locomotion, etc.).
PL. - PED.-ABD.

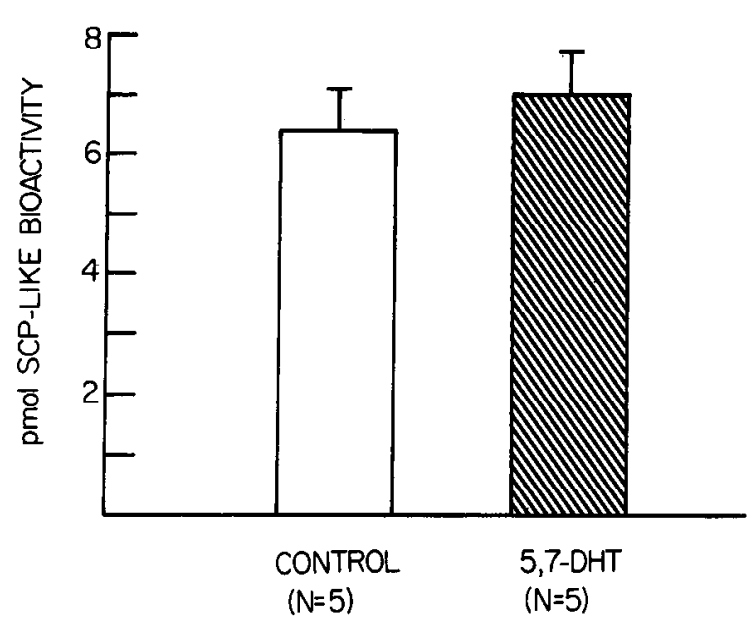

Figure 13. Quantification of the results of the bioassay measuring the content of peptides $\mathrm{SCP}_{\mathrm{A}}$ and $\mathrm{SCP}_{\mathrm{B}}$ in central ganglia from control and 5,7-DHT-treated animals. As in the HPLC analysis, single pleural, ped$\mathrm{al}$, and abdominal ganglia from each of 5 control and 5 5,7-DHT-treated animals were processed together for the bioassay (see Materials and Methods). The histogram shows the mean SCP-like (both $\mathrm{SCP}_{\mathrm{A}}$ and $\mathrm{SCP}_{\mathrm{B}}$ ) bioactivity in fractions of the combined ganglia; the error bars are S.E.M. The difference between the control and toxin-treated ganglia was not statistically significant $(p>0.5)$.

Our data suggest that tail, as well as mantle, shocks activate a broadly distributed serotonergic system in the Aplysia CNS which modulates the neural circuitry mediating a variety of behavioral responses. Thus, 5,7-DHT treatment not only reduces the ability of tail and mantle shocks to enhance gill- and siphon-withdrawal; it also reduces the increase in spontaneous gill contractions that tail and mantle shocks typically produce. Furthermore, in electrophysiological experiments on the pleural-pedal ganglia similar those described here for the abdominal ganglion we found that 5,7-DHT treatment significantly reduces facilitation of the complex EPSP in tail motor neurons following tail shock (Glanzman et al., 1986, and unpublished observations).

\section{5-HT and learning in invertebrates}

It is becoming increasingly apparent that 5-HT plays a critical role in the neural mechanisms of certain types of memory stor-

Figure 12. Fluorescence micrographs of glyoxylic-acid-stained tissue from control and 5,7-DHT-treated animals. $A_{l}$, Fluorescence micrograph of a cryostat section of an abdominal ganglion from a control animal. The yellow staining indicates 5-HT-containing structures, the blue staining DAcontaining structures. As previously shown (Kistler et al., 1985), a network of 5-HT-containing fibers and varicosities surrounds the cell bodies of cells in the abdominal ganglion. There is also a dense plexus of both 5-HT- and DA-containing fibers in the central neuropil. In this micrograph a medium-size 5-HT-containing cell body as well as several small 5-HT-containing cell bodies can be seen in the upper left-hand corner. $A_{2}$, Fluorescence micrograph of a cryostat section of an abdominal ganglion from a 5,7-DHT-treated animal. The network of 5-HT-containing varicosities and fibers surrounding the cell bodies has been eliminated. (The residual reddish brown staining-which can also be seen, although less clearly, in the micrograph of the control abdominal ganglion-represents autofluorescence.) The plexus of 5-HT-containing fibers in the central neuropil is also reduced. (The large globs of yellow below the surface of the ganglion represent parts of 5-HT-containing cell bodies or large 5-HT-containing processes.) The DA staining, by contrast, appears completely unaffected by the neurotoxin. Note that the staining of the large and medium size 5-HT-containing cell bodies is reduced, but far from eliminated. $B_{l}$, Fluorescence micrograph of a buccal ganglion from a control animal. The fine network of 5-HT-containing (yellow) fibers and varicosities surrounding the cell bodies is particularly dramatic in this ganglion. Also visible is a portion of a nexus of DA-containing (blue) fibers in the central neuropil, as well as a DA-containing cell body. The buccal ganglion has no 5-HTcontaining cell bodies. $B_{2}$, Fluorescence micrograph of a cryostat section of a buccal ganglion from a 5,7-DHT-treated animal. All 5-HT-dependent staining has been eliminated. The DA-dependent staining is still prominent after the toxin treatment. Note that this particular section did not intersect a DA-containing cell body.) 
age for a wide variety of invertebrates. Thus, depletion of 5-HT, either via 5,7-DHT treatment or (in one case) a single-gene mutation, has been shown to disrupt various types of nonassociative and associative learning in the crayfish (Glanzman and Krasne, 1986), the fruitfly (Aceves-Piña et al., 1983), and several different snails, including Helix (Balaban et al., 1987; Zakharov and Balaban, 1987), Hermissenda (Grover and Farley, 1986), and, now, Aplysia. Of special interest here is the work of Balaban and his colleagues. Balaban et al. (1987) found that 5,7-DHT treatment significantly interfered not only with sensitization of Helix's withdrawal responses, but also with classical conditioning of food aversion in this snail. These results accord well with the model of classical conditioning of $A p l y s i a$ 's gill- and siphonwithdrawal response proposed by Hawkins et al. (1983), whereby a cellular mechanism mediating classical conditioning (activity-dependent presynaptic facilitation) is an elaboration of a cellular mechanism mediating dishabituation and sensitization (presynaptic facilitation). Since our results suggest that 5-HT is required for dishabituation and sensitization of withdrawal in Aplysia, it will be interesting to determine whether 5-HT is also required for classical conditioning of this response.

\section{References}

Abrams, T. W., V. F. Castellucci, J. S. Camardo, E. R. Kandel, and P. E. Lloyd (1984) Two endogenous neuropeptides modulate the gill and siphon withdrawal reflex in Aplysia by presynaptic facilitation involving CAMP-dependent closure of a serotonin-sensitive potassium channel. Proc. Natl. Acad. Sci. USA 81: 7956-7960.

Aceves-Piña, E. O., R. Booker, J. S. Duerr, M. S. Livingston, W. G. Quinn, R. F. Smith, P. P. Sziber, B. L. Tempel, and T. P. Tully (1983) Learning and memory in Drosophila, studied with mutants. Cold Spring Harbor Symp. Quant. Biol. 48: 831-840.

Bailey, C. H., R. D. Hawkins, M. C. Chen, and E. R. Kandel (1981) Interneurons involved in mediation and modulation of gill-withdrawal reflex in Aplysia. IV. Morphological basis of presynaptic facilitation. J. Neurophysiol. 45: 340-360.

Bailey, C. H., R. D. Hawkins, and M. C. Chen (1983) Uptake of ['H]serotonin in the abdominal ganglion of Aplysia californica. Further studies on the morphological and biochemical basis of presynaptic facilitation. Brain Res. 272: 71-81.

Balaban, P. M., A. Vehovsky, O. A. Maximova, and I. S. Zakharov (1987) Effect of 5,7-dihydroxytryptamine on the food-aversive conditioning in the snail Helix lucorum L. Brain Res. 404: 201-210.

Baumgarten, H. G., S. Jenner, A. Bjorklund, H. P. Klemin, and H. G. Schlossberger (1982) Serotonin neurotoxins. In Biology of Serotonergic Transmission, N. N. Osborne, ed., pp. 249-277, Wiley, New York.

Bernier, L., V. F. Castellucci, E. R. Kandel, and J. H. Schwartz (1982) Facilitatory transmitter causes a selective and prolonged increase in adenosine $3^{\prime}: 5^{\prime}$-monophosphate in sensory neurons mediating the gill and siphon withdrawal reflex in Aplysia. J. Neurosci. 2: 1682-1691.

Castellucci, V., and E. R. Kandel (1976) Presynaptic facilitation as a mechanism for behavioral sensitization in Aplysia. Science 194: 11761178.

Castellucci, V., H. Pinsker, I. Kupfermann, and E. R. Kandel (1970) Neuronal mechanisms of habituation and dishabituation of the gillwithdrawal reflex in Aplysia. Science 167: 1745-1748.

Castellucci, V. F., A. Nairn, P. Greengard, J. H. Schwartz, and E. R. Kandel (1982) Inhibitor of adenosine 3':5'-monophosphate-dependent protcin kinase blocks presynaptic facilitation in Aplysia. J. Neurosci. 2: 1673-1681.

de La Torre, J. C., and J. W. Surgeon (1976) Histochemical fluorescence of tissues and brain monoamines: Results in 18 minutes using the sucrose-phosphate-glyoxylic acid (SPG) method. Neuroscience 1: 451-453.

Frankfurt, M., and E. Azmitia (1984) Regeneration of serotonergic fibers in the rat hypotholamus following unilateral 5,7-dihydroxytryptamine injection. Brain Res. 298: 273-282.

Frost, W. N. (1987) Mechanisms Contributing to Short- and Long-
Term Sensitization in Aplysia. Ph.D. Dissertation, Columbia University, New York.

Frost, W. N., G. A. Clark, and E. R. Kandel (1988) Parallel processing of short-term memory for sensitization in Aplysia. J. Neurobiol. 19: 297-334.

Gadotti, D., L. G. Bauce, K. Lukowiak, and A. G. M. Bulloch (1986) Transient depletion of serotonin in the nervous system of Helisoma. J. Neurobiol. 17: 431 -447 .

Glanzman, D. L., and F. B. Krasne (1986) 5,7-Dihydroxytryptamine lesions of crayfish serotonin-containing neurons: Effect on the lateral giant escape reaction. J. Neurosci. 6: 1560-1569.

Glanzman, D. L., S. Mackey, and E. R. Kandel (1986) Depletion of serotonin in Aplysia interferes with facilitation produced by sensitizing stimuli. Soc. Neurosci. Abstr. 12: 1339.

Glover, J. C., and A. P. Kramer (1982) Serotonin analogue selectively ablates identified neurons in the leech embryo. Science 216: 10121014.

Goldberg, J. I., and S. B. Kater (1985) Experimental reduction of serotonin content during embryogenesis alters morphology and connectivity of specific identified Helisoma neurons. Soc. Neurosci. Abstr. 11: 158.

Grover, L., and J. Farley (1986) Serotonin mediates in vitro conditioning effects on Type B photoreceptors in Hermissenda. Soc. Neurosci. Abstr. 12: 1338.

Hawkins, R. D. (1989) Localization of potential serotonergic facilitator neurons in Aplysia by glyoxylic acid histofluorescence combined with retrograde fluorescent labeling. J. Neurosci. 9: 4214-4226.

Hawkins, R. D., and S. Schacher (1989) Identified facilitator neurons L29 and L 28 are excited by cutaneous stimuli used in dishabituation, sensitization, and classical conditioning of Aplysia. J. Neurosci. 9: $4236-4245$.

Hawkins, R. D., and S. A. Small (1988) An identified FMRFamideimmunoreactive neuron produces presynaptic inhibition of the siphon sensory neurons in Aplysia. Soc. Neurosci. Abstr. 14: 842.

Hawkins, R. D., V. F. Castellucci, and E. R. Kandel (1981a) Interneurons involved in mediation and modulation of gill-withdrawal reflex in Aplysia. I. Identification and characterization. J. Neurophysiol. 45: 304-314.

Hawkins, R. D., V. F. Castellucci, and E. R. Kandel (1981b) Interneurons involved in mediation and modulation of gill-withdrawal reflex in Aplysia. II. Identified neurons produce heterosynaptic facilitation contributing to behavior sensitization. J. Neurophysiol. 445: 315-326.

Hawkins, R. D., T. W. Abrams, T. J. Carew, and E. R. Kandel (1983) A cellular mechanism of classical conditioning in Aplysia: Activitydependent amplification of presynaptic facilitation. Science $219: 400$ 405.

Hochner, B., M. Klein, S. Schacher, and E. R. Kandel (1986) Additional component in the cellular mechanism of presynaptic facilitation contributes to behavioral dishabituation in Aplysia. Proc. Natl. Acad. Sci. USA 983: 8794-8798.

Jahan-Parwar, B., K. S.-Rozsa, J. Salanki, M. L. Evans, and D. O. Carpenter (1987) In vivo labeling of serotonin-containing neurons by 5,7-dihydroxytryptamine in Aplysia. Brain Res. 426: 173-178.

Kanz, J. E., L. B. Eberly, J. S. Cobbs, and H. M. Pinsker (1979) Neuronal correlates of siphon withdrawal in freely behaving Aplysia. J. Neurophysiol. 42: 1538-1556.

Kistler, H. B., Jr., R. D. Hawkins, J. Koester, H. W. M. Steinbusch, E. R. Kandel, and J. H. Schwartz (1985) Distribution of serotoninimmunoreactive cell bodies and processes in the abdominal ganglion of mature Aplysia. J. Neurosci. 5: 72-80.

Klein, M., and E. R. Kandel (1978) Presynaptic modulation of voltagedependent $\mathrm{Ca}^{2+}$ current: Mechanism for behavioral sensitization in Aplysia californica. Proc. Natl. Acad. Sci. USA 75: 3512-3516.

Klein, M., J. Camardo, and E. R. Kandel (1982) Serotonin modulates a specific potassium current in the sensory neurons that show presynaptic facilitation in Aplysia. Proc. Natl. Acad. Sci. USA 79: 57135717.

Klein, M., B. Hochner, and E. R. Kandel (1986) Facilitatory transmitters and cAMP can modulate accommodation as well as transmitter release in Aplysia sensory neurons: Evidence for parallel processing in a single cell. Proc. Natl. Acad. Sci. USA 83: 7994-7998.

Kupfermann, I., V. Castellucci, H. Pinsker, and E. R. Kandel (1970) Neuronal correlates of habituation and dishabituation of the gillwithdrawal reflex in Aplysia. Science 167: 1743-1745. 
Lent, C. M. (1984) Quantitative effects of a neurotoxin upon serotonin levels within tissue compartments of the medicinal leech. J. Neurobiol. 15: 309-323.

Lent, C. M., and M. H. Dickinson (1984) Serotonin integrates the feeding behavior of the medicinal leech. J. Comp. Physiol. 154: 457471.

Livingstone, M. S., S. F. Schaeffer, and E. A. Kravitz (1981) Biochemistry and ultrastructure of serotonergic endings in the lobster: serotonin and octopamine are contained in different nerve endings. J. Neurobiol. 12: 27-54.

Lloyd, P. E. (1978) Distribution and molecular characteristics of cardioactive peptides in the snail, Helix aspersa. J. Comp. Physiol. 128. 269-276.

Longley, R. D., and A. J. Longley (1986) Serotonin immunoreactivity of neurons in the gastropod Aplysia californica. J. Neurobiol. 17:339358.

Mackey, S., and T. J. Carew (1983) Locomotion in Aplysia: Triggering by serotonin and modulation by bag cell extract. J. Neurosci. 3: 1469 1477.

Mackey, S. L., D. L. Glanzman, S. A. Small, A. M. Dyke, E. R. Kandel, and R. D. Hawkins (1987) Tail shock produces inhibition as well as sensitization of the siphon-withdrawal reflex of Aplysia: Possible behavioral role for presynaptic inhibition mediated by the peptide Phe-Met-ARg-Phe-NH, Proc. Natl. Acad. Sci. USA 84: 8730-8734.

Mackey, S. L., E. R. Kandel, and R. D. Hawkins (1989) Identified serotonergic neurons LCB1 and RCB1 in the cerebral ganglia of $A p l y-$ sia produce presynaptic facilitation of siphon sensory neurons. J. Neurosci. 9: 4227-4235.

Marcus, E A., T. G. Nolen, C. H. Rankin, and T. J. Carew (1988) Behavioral dissociation of dishabituation, sensitization, and inhibition in Aplysia. Science 241: 210-213.
Montarolo, P. G., P. Goelet, V. F. Castellucci, J. Morgan, E. R. Kandel, and S. Schacher (1986) A critical period for macromolecular synthesis in long-term heterosynaptic facilitation in Aplysia. Science 234: 1249-1254.

Nobin, A., H. G. Baumgarten, A. Bjorkland, L. Lachenmayer, and U. Stenevi (1973) Axonal degeneration and regeneration of the bulbospinal indoleamine neurons after 5,6-dihydroxytryptamine treatment. Brain Res. 56: 1-24.

Nolen, T. G., J. A. Mindell, and T. J. Carew (1986) Development of ncurotransmitters implicated in learning by Aplysia. Soc. Neurosci. Abstr. 12: 399.

Ono, J., and R. E. McCaman (1984) Immunocytochemical localization and direct assays of serotonin-containing neurons in Aplysia. Neuroscience 11: 549-560.

Pinsker, H., I. Kupfermann, V. Castellucci, and E. R. Kandel (1970) Habituation and dishabituation of the gill-withdrawal reflex in Aplysia. Science 167: 1740-1742.

Rankin, C. H., and T. J. Carew (1988) Dishabituation and sensitization emerge as separate processes during development in Aplysia. J. Neurosci. 8: 197-211.

Siegelbaum, S. A., J. S. Camardo, and E. R. Kandel (1982) Serotonin and cyclic AMP close single $\mathrm{K}^{+}$channels in Aplysia sensory neurones. Nature 299: 413-417.

Walters, E. T., J. H. Byrne, T. J. Carew, and E. R. Kandel (1983) Mechanoafferent neurons innervating tail of Aplysia. I. Response properties and synaptic connections. J. Neurophysiol. 50: 1522-1542.

Zakharov, I. S., and P. M. Balaban (1987) Neural mechanisms of agedependent changes in avoidance behavior of the snail Helix lucorum. Neuroscience 23: 721-729. 